\title{
Estimativa da Produção de Proteína Microbiana pelos Derivados de Purinas na Urina em Novilhos ${ }^{1}$
}

\author{
Luciana Navajas Rennó ${ }^{2}$, Rilene Ferreira Diniz Valadares ${ }^{3}$, Maria Ignez Leão ${ }^{4}$, Sebastião de \\ Campos Valadares Filho ${ }^{4}$, José Fernando Coelho da Silva ${ }^{5}$, Paulo Roberto Cecon ${ }^{6}$, Helder Luiz \\ Chaves Dias ${ }^{7}$, Marco Antônio Lana Costa ${ }^{9}$, Rodrigo Vidal de Oliveira ${ }^{8}$
}

\begin{abstract}
RESUMO - O trabalho foi realizado para avaliar a determinação da produção de proteína microbiana com a utilização da excreção urinária de derivados de purinas; comparar a produção de proteína microbiana por intermédio dos métodos das bases purinas e da excreção urinária de derivados de purinas; determinar a produção de proteína microbiana em função do consumo de matéria seca e da porcentagem de fibra em detergente neutro da ração; e estabelecer a proporção de alantoína e ácido úrico, em relação à xantina e hipoxantina na urina. Foram realizados cinco experimentos com animais fistulados no rúmen, abomaso e íleo para estudos simultâneos de consumo, digestões totais e parciais de nutrientes e eficiência de síntese de proteína microbiana. Utilizou-se o delineamento experimental em quadrado latino $5 \times 5$, à exceção do experimento IV $(4 \times 4)$. Os dados foram agrupados em todos os experimentos, os que envolveram animais mestiços (I, II e III) e zebuínos (IV e V). Utilizou-se, para todos os dados agrupados, o delineamento inteiramente casualizado, em função dos níveis de concentrado da dieta. Da urina total coletada em 24 horas, foram analisados os derivados de purinas (alantoína, ácido úrico, xantina e hipoxantina) para determinar a produção microbiana. Para todos os experimentos agrupados, as excreções de derivados de purinas urinários, representadas pela alantoína e pelas purinas totais, apresentaram comportamento quadrático em função dos níveis de concentrado da ração, acompanhando o comportamento do fluxo de compostos nitrogenados microbianos ( $\mathrm{N}$ mic) estimado pelos derivados de purinas na urina, usando a relação $\mathrm{N}$ purina: $\mathrm{N}$ total de 0,116 , e o estimado pelas bases purinas no abomaso, encontrando-se valores máximos de 72,07 e $86,08 \mathrm{~g} \mathrm{~N}$ mic/dia, para níveis de 62,91 e 63,60\% de concentrado, respectivamente. A relação alantoína e ácido úrico:purinas totais foi de, aproximadamente, $98 \%$, indicando que a concentração de xantina e hipoxantina seria, em torno, de $2 \%$.
\end{abstract}

Palavras-chave: nitrogênio microbiano, novilhos, purinas na urina

\section{Microbial Protein Production Obtained by the Urinary Purine Derivatives in Steers}

\begin{abstract}
The work was carried out to evaluate the microbial protein production determination by means of the urinary excretion of purine derivatives; to compare the microbial protein production by means of purine base methods and of the urinary excretion of purine derivatives; to determine the microbial protein production on the dry matter intake and percentage of neutral detergent fiber in the diet; and to establish the allantoin: uric acid ratio, in relation to the xanthine and hypoxanthine in the urine. Five experiments were carried out with steers fistulated in the rumen, abomasum and ileum, for simultaneous studies of intake, total and partial nutrient digestion and efficiency of microbial protein synthesis. An experimental 5 x 5 Latin square design, except for the experiment IV ( 4 x 4), was used. Data were grouped in all the experiments, the ones that involved crossbred animals (I, II and III) and Zebu animals (IV and V). For all grouped data, a completely randomized design was used in function of the dietary concentrate levels. From the total urine collected in 24 hours, the purine derivatives (allantoin, uric acid, xanthine and hypoxanthine) were analyzed to determine the microbial production. For all experiments urinary purine derivatives excretions, represented by the allantoin and the total purine, presented quadratic behavior on the dietary concentrate levels, according to the $\mathrm{N}$ mic flow behavior estimated by the urinary purine derivatives excretions, using purine $\mathrm{N}$ : total purine ratio of .116 and the estimated by the purine bases in the abomasum, reaching maximum values of 72.07 and $86.08 \mathrm{~N}$ $\mathrm{mic} /$ day for concentrate levels of 62.91 and $63.60 \%$, respectively. Allantoin: uric acid ratio was nearly to $98 \%$, indicating that the xanthine and hypoxanthine concentration would be around $2 \%$.
\end{abstract}

Key Words: microbial nitrogen, purine in the urine, steers

\footnotetext{
1 Parte da Tese apresentada à UFV, para obtenção do título "Magister Scientiae". Projeto financiado parcialmente pela FAPEMIG.

2 Estudante de Doutorado da UFV. E.mail: Inrenno@alunos.ufv.br

${ }^{3}$ Professor do Departamento de Medicina Veterinária/UFV.

${ }^{4}$ Professor do Departamento de Zootecnia/UFV.

5 Professor da UENF. Campos dos Goytacazes, RJ.

6 Professor do Departamento de Matemática.

${ }^{7}$ Professor do Departamento de Zootecnia/UEMA.

${ }^{8}$ Estudante de Mestrado/UFV.

${ }^{9}$ Estudante de Graduação/UFV.
} 


\section{Introdução}

As exigências protéicas dos ruminantes são atendidas mediante a absorção intestinal de aminoácidos provenientes, principalmente, da proteína microbiana sintetizada no rúmen e da proteína dietética não-degradada no rúmen (VALADARES FILHO, 1995). Trabalhos de pesquisa indicaram que a proteína microbiana responde, em média, por $59 \%$ da proteína que chega ao intestino delgado (CLARK et al., 1992), o que denota a importância do estudo dos mecanismos de síntese protéica bacteriana e dos fatores a eles relacionados (NOCEK e RUSSELL, 1988).

A obtenção de dados da produção de proteína microbiana no rúmen tem sido lenta, principalmente pelo fato de os métodos estabelecidos serem trabalhosos, demorados e requererem animais preparados cirurgicamente (STANGASSINGER et al., 1995; VAGNONI et al., 1997).

As pesquisas, ao longo dos últimos anos, confirmaram a relação entre produção de proteína microbiana e excreção urinária de derivados de purinas (PEREZ et al., 1996). Então, assumiu-se que a absorção de purinas estaria condicionada à quantidade de proteína microbiana, estimada a partir da excreção urinária dos derivados de purinas:alantoína, ácido úrico, xantina e hipoxantina (GIESECKE et al., 1994).

PUCHALA e KULASEK (1992) observaram correlação positiva entre o fluxo de $\mathrm{N}$ microbiano e a excreção urinária de derivados de purinas em carneiros e, ainda, comparando os métodos do ácido nucléico microbiano e da excreção de derivados de purinas na urina, obtiveram alta correlação. JOHNSON et al. (1998) e VAGNONI et al. (1997) também concluíram que a excreção urinária de derivados de purinas apresentou correlação positiva na estimativa do fluxo de $\mathrm{N}$ microbiano no duodeno.

A excreção de derivados de purinas está diretamente relacionada com a absorção de purinas e, com o conhecimento da relação $\mathrm{N}$ purina: $\mathrm{N}$ total, na massa microbiana, a absorção de $\mathrm{N}$ microbiano pode ser calculada a partir da quantidade de purina absorvida, que é estimada por intermédio da excreção urinária de derivados de purinas (CHEN e GOMES, 1992).

A excreção urinária de derivados de purinas, pelos ruminantes, pode ser usada para estimar o fluxo intestinal de proteína microbiana, uma vez que a excreção endógena de derivados de purinas e a relação quantitativa entre a excreção de derivados de purinas e a absorção de purina tenham sido previamente determinadas (CHEN et al., 1996). Segundo os mesmos autores, há diferenças no metabolismo das purinas, sendo já estabelecido que ovinos e Bos taurus diferem quanto ao nível de excreção endógena de purinas e à habilidade de utilização de purinas de origem exógena.

As purinas são prontamente absorvidas como nucleosídeos e bases livres no lúmen do intestino delgado e estão sujeitas à degradação extensiva por enzimas específicas, como guanina deaminase, adenosina deaminase e xantina oxidase, em sua passagem através da mucosa intestinal. É importante salientar que a extensão desta degradação determina a disponibilidade metabólica das purinas a serem utilizadas pelos animais (STANGASSINGER et al., 1995).

Tem-se, por intermédio da ação da enzima-chave na degradação das purinas, a xantina oxidase, a conversão de hipoxantina em xantina e ácido úrico; este, então, é degradado em alantoína, pela ação da uricase (LEHNINGER, 1995).

Segundo STANGASSINGER et al. (1995), existe pouca informação sobre a excreção de purinas em gado zebu (Bos indicus). Embora considerem improvável, MURA et al. (1986) relataram que estes animais não têm uricase no fígado, porém outras enzimas, como a xantina oxidase, estão presentes no tecido hepático.

Na urina de bovinos, ambas as purinas endógenas e exógenas têm composição semelhante de, aproximadamente, $85 \%$ de alantoína e $15 \%$ de ácido úrico; xantina e hipoxantina não estão presentes em quantidades significativas na urina de bovinos (CHEN et al., 1990a, b; VERBIC et al., 1990; e CHEN e GOMES, 1992).

FUNABA et al. (1997), VAGNONI et al. (1997) e MOSCARDINI et al. (1998) utilizaram somente as excreções de alantoína e ácido úrico para representar o total de excreção urinária de derivados de purinas. No entanto, LIANG et al. (1994) determinaram, além dos derivados de purinas supracitados, também xantina e hipoxantina. A maioria dos estudos não utilizou a determinação destes últimos derivados para bovinos, pois, nesta espécie, verifica-se alta atividade da enzima xantina oxidase na conversão de xantina e hipoxantina em ácido úrico (CHEN e GOMES, 1992).

A estimativa do fluxo de proteína microbiana no duodeno, a partir da excreção de derivados de purinas na urina, necessita do conhecimento da relação $\mathrm{N}$ purina: $\mathrm{N}$ total dos microrganismos ruminais, que é 
bastante variável (VAGNONI e BRODERICK, 1997). CHEN e GOMES (1992) utilizaram relação igual a 0,116, a partir de dados da literatura. VALADARES FILHO (1995) relatou valores médios de 0,176, obtidos de dez experimentos. DIAS (1999), CARDOSO (1999), TIBO (1999), RIBEIRO (1999) e CARVALHO et al. (1997b) obtiveram relações de 0,$113 ; 0,104 ; 0,069 ; 0,146$; e 0,153 , respectivamente, em seus experimentos.

As disponibilidades ruminais de energia e $\mathrm{N}$ são os fatores nutricionais que mais limitam o crescimento microbiano (CLARK et al., 1992). Esses autores verificaram que a alteração da relação volumoso:concentrado na dieta poderia influir no crescimento microbiano, em razão da variação na disponibilidade de energia.

A energia para a síntese de proteína microbiana é oriunda principalmente dos carboidratos dietéticos cuja fonte pode afetar o crescimento microbiano. Se os carboidratos não-estruturais (CNE) estiverem em alta proporção na ração e o $\mathrm{pH}$ for mantido, os microrganismos fermentadores deste substrato vão crescer rapidamente, resultando em aumento da produção microbiana. Por outro lado, se houver acúmulo de ácido lático, ocorrerá diminuição do $\mathrm{pH} \mathrm{e}$ alteração na ecologia microbiana e no consumo de matéria seca (SNIFFEN e ROBINSON, 1987).

Taxas mais rápidas de crescimento, associadas à passagem mais rápida de microrganismos para o intestino delgado, podem reduzir a reciclagem de energia e $\mathrm{N}$ no rúmen, decorrente de decréscimo na lise das células, diminuindo, assim, os requisitos de mantença dos microrganismos e, conseqüentemente, fornecendo mais nutrientes para o crescimento microbiano (CLARK et al., 1992).

A produção microbiana, segundo VALADARES FILHO (1995), tem sido expressa de diferentes formas: em função dos nutrientes digestíveis totais NDT (NRC, 1985), da matéria orgânica degradada no rúmen - MODR (AGRICULTURAL RESEARCH COUNCIL - ARC, 1984), da energia metabolizável fermentável da dieta (AGRICULTURAL AND FOOD RESEARCH COUNCIL - AFRC, 1993) e dos carboidratos totais degradados no rúmen CHODR (CNCPS, descrito por RUSSELL et al., 1992). De acordo com esses autores, a melhor forma de expressar a eficiência microbiana seria em relação aos CHODR, em comparação com a MODR e o NDT, pois os carboidratos constituem a principal fonte de energia para os microrganismos ruminais, quando comparados a lipídeos e proteína bruta. Em- bora esta última possa contribuir como fonte energética, via fermentação dos esqueletos de carbono, derivados da deaminação de aminoácidos, esta não é sua principal função no rúmen. Os lipídeos praticamente não fornecem energia para os microrganismos.

A excreção urinária de derivados de purinas pode ser considerada método simples e não-invasivo para estimar a produção microbiana, entretanto, de acordo com PEREZ et al. (1996), seu uso necessita de validação pela comparação de estimativas com outras técnicas.

O presente trabalho foi conduzido com os objetivos de avaliar a produção de proteína microbiana, por intermédio da utilização da excreção urinária dos derivados de purinas; determinar a produção de proteína microbiana, em função do consumo de matéria seca e da porcentagem de fibra em detergente neutro da ração; comparar a produção de proteína microbiana entre os métodos das bases purinas e da excreção urinária de derivados de purinas; e estabelecer a relação dentro dos derivados de purinas, alantoína e ácido úrico, em relação à xantina e hipoxantina.

\section{Material e Métodos}

O presente experimento foi conduzido nas dependências do Laboratório de Animais e do Laboratório de Nutrição Animal do Departamento de Zootecnia do Centro de Ciências Agrárias da Universidade Federal de Viçosa, em Viçosa, MG.

Foram realizados cinco experimentos, que constituíram teses de Mestrado, DIAS (1999); CARDOSO (1999) e TIBO (1999), e Doutorado, RIBEIRO (1999) e CARVALHO (1996), correspondendo, respectivamente, aos experimentos I, II, III, IV e V.

Nos experimentos I e II, foram utilizados cinco novilhos mestiços F1 Limousin x Nelore, não-castrados, com idade média de 15 meses e peso vivo médio inicial de 268 e $279 \mathrm{~kg}$, respectivamente, alimentados com rações constituídas de 25,0; 37,5; 50,0; 62,5; e $75,0 \%$ de concentrado (na base da matéria seca) e feno de capim-coastcross (Cynodon dactylon), formuladas para terem níveis variados de proteína, de acordo com a energia da dieta, segundo o NRC (1996), ou conterem, aproximadamente, $12 \%$ de PB, de acordo com o NRC (1984), respectivamente.

No experimento III, foram utilizados cinco novilhos mestiços F1 Simental x Nelore, não-castrados, com idade de 18 meses e peso vivo médio inicial de 
$300 \mathrm{~kg}$, alimentados com rações constituídas de 25,0; 37,$5 ; 50,0 ; 62,5 ;$ e 75,0\% de concentrado (na base da matéria seca) e fenos dos capins coast-cross e brachiaria (Brachiaria decumbens) em proporções iguais, formuladas para terem níveis variados de proteína de acordo com a energia da dieta, segundo o NRC (1996).

No experimento IV, foram utilizados quatronovilhos zebuínos (Nelore) não-castrados, com idade média de 20 meses e peso vivo médio inicial de $300 \mathrm{~kg}$, alimentados com rações contendo feno de capim Tifton-85 (Cynodon spp), colhido com 28, 35, 42 e 56 dias de rebrota, como fonte de volumoso, e $40 \%$ de concentrado.

No experimento $\mathrm{V}$, foram utilizados cinco novilhos zebuínos (Nelore), não-castrados, com idade média de 18 meses e peso vivo médio inicial de 186 $\mathrm{kg}$, alimentados com rações constituídas de 20,0; 32,$5 ; 45,0 ; 57,5 ;$ e 70,0\% de concentrado (na base da matéria seca) e feno de capim-elefante (Pennisetum purpureum), formuladas para conterem $12 \%$ de PB.

Em todos os experimentos, os animais foram fistulados no rúmen, abomaso e íleo, segundo as técnicas descritas por LEÃO e COELHO DA SILVA (1980), e foi realizado estudo simultâneo de digestão total e parcial de nutrientes, eficiência microbiana, taxa de passagem, $\mathrm{pH}$ e concentração de amônia ruminais.

Utilizou-se delineamento experimental em quadrado latino $5 \times 5$, com cinco animais, cinco tratamentos (níveis de concentrado) e cinco períodos experimentais para os ensaios I, II, III e V, enquanto para o IV, quadrado latino $4 \times 4$, com quatro animais, quatro tratamentos (feno em quatro idades de rebrota) e quatro períodos experimentais.

Após as análises feitas para cada experimento, os dados referentes aos experimentos I, II, III, IV e $\mathrm{V}$ foram agrupados em todos os experimentos, os que envolveram animais mestiços (I, II e III) e zebuínos (IV e V). Utilizou-se, para os dados agrupados, o delineamento inteiramente casualizado, em função dos níveis de concentrado.

Os constituintes e a composição química das rações dos experimentos I, II, III, IV e V foram descritos por DIAS (1999), CARDOSO (1999), TIBO (1999), RIBEIRO (1999) e CARVALHO et al. (1997a), respectivamente.

Os experimentos I, II, III e V e o experimento IV constaram de cinco e quatro períodos experimentais, respectivamente, cada um com duração aproximada de 17 dias, sendo 10 dias de adaptação e seis dias para coleta de amostras do ensaio de digestibilidade e um dia para coleta de urina, sendo o sangue coletado ao final do período de coleta de urina.

Para as coletas de urina, com duração de 24 horas, foram utilizados funis coletores, adaptados aos animais, conforme metodologia descrita por VALADARES et al. (1997). Da urina total coletada em recipiente contendo $200 \mathrm{~mL}$ de $\mathrm{H}_{2} \mathrm{SO}_{4}$, a $10 \%$, no período de 24 (experimentos I, II, IV e V) e 12 horas (experimento III), após pesagem e homogeneização, foram obtidas alíquotas de $100 \mathrm{~mL}$. Estas amostras tiveram o pH ajustado abaixo de 3 e foram diluídas 3 a 4 vezes, para evitar destruição bacteriana dos derivados de purinas urinários e precipitação do ácido úrico.

As análises de derivados de purinas (alantoína, ácido úrico, xantina e hipoxantina) foram feitas pelo método colorimétrico, conforme técnica de FUJIHARA et al. (1987), descrita por CHEN e GOMES (1992). A determinação de alantoína foi descrita por Young e Conway (1942), citados por CHEN e GOMES (1992), e baseia-se na hidrólise alcalina a $100^{\circ} \mathrm{C}$ da alantoína a ácido alantóico, que, posteriormente, é convertido em uréia e ácido glioxílico em solução ácida. O ácido glioxílico reage, então, com hidrocloreto de fenilhidrazina, para produzir fenilhidrazona do ácido. O produto forma um cromógeno instável, com ferricianeto de potássio, que pode ser dosado, colorimetricamente, a $522 \mathrm{~nm}$. O método descrito por FUJIHARA et al. (1987), para determinação de ácido úrico, baseia-se no tratamento da amostra de urina com uricase, resultando em alantoína, que não absorve ultra-violeta (UV) a $293 \mathrm{~nm}$. Então, a redução na leitura de absorbância a 293 nm foi correlacionada com a concentração de ácido úrico. Para determinação de xantina e hipoxantina, estas foram convertidas em ácido úrico pela xantina oxidase e medidas como ácido úrico a $293 \mathrm{~nm}$, conforme descrito por CHEN e GOMES (1992).

A técnica de determinação da produção de proteína microbiana pelas bases purinas, usando coletas de digestas de abomaso, foi adotada nos experimentos simultâneos de digestibilidade. Aproximadamente dois litros de digesta de rúmen de cada animal foram coletados via fístula ruminal, e as bactérias isoladas conforme CECAVA et al. (1990). Ao final dos experimentos, foram feitas amostras compostas para cada raçãoe, para medir a produção de biomassa microbiana, foram utilizadas as bases purinas, determinadas conforme recomendações de USHIDA et al. (1985).

As purinas microbianas absorvidas ( $\mathrm{X}, \mathrm{mmol} / \mathrm{dia})$ foram calculadas a partir da excreção de derivados 
de purinas ( $\hat{Y}, \mathrm{mmol} / \mathrm{dia})$, por intermédio da equação: $\hat{\mathrm{Y}}=0,85 \mathrm{X}+0,385 \mathrm{PV}^{0,75}$, em que 0,85 é a recuperação de purinas absorvidas como derivados urinários de purinas e $0,385 \mathrm{PV}^{0,75}$, a contribuição endógena para a excreção de purinas (VERBIC et al., 1990).

O fluxo intestinal de compostos nitrogenados (N) microbianos ( $\hat{Y}, g$ N/dia) foi calculado em função das purinas microbianas absorvidas (X, mmol/dia), utilizando-se a equação $\hat{Y}=(70 X) /(0,83 \times 0,116 \times 1000)$, em que 70 representa o conteúdo de $\mathrm{N}$ nas purinas (mg N/mmol); 0,83, a digestibilidade das purinas microbianas; e 0,116 , a relação $\mathrm{N}$-purina: $\mathrm{N}$-total nas bactérias (CHEN e GOMES, 1992). Também foi calculado o fluxo de $\mathrm{N}$ microbiano, por intermédio da relação $\mathrm{N}$ purina: $\mathrm{N}$ total, obtido para cada experimento de 0,$113 ; 0,104 ; 0,069 ; 0,146 ;$ e 0,153 , respectivamente, para os experimentos I, II, III, IV e V.

Foram ajustadas equações de regressão entre a quantidade de proteína microbiana sintetizada diariamente (Y), utilizando-se coletas no abomaso, e a quantidade de proteína microbiana, com derivados de bases purinas na urina (X). Foi efetuado, também, teste " $t$ " entre estas duas variáveis. Os dados foram avaliados por meio de análises de variância e regressão, utilizando-se o programa SAEG - Sistema de Análises Estatísticas e Genéticas (UNIVERSIDADE FEDERAL DE VIÇOSA - UFV, 1995).

\section{Resultados e Discussão}

Na Tabela 1, são apresentados os dados agrupados para todos os experimentos; I, II, III, IV e V, totalizando 116 observações. Constam da Tabela 1 as excreções diárias de derivados de purinas, alantoína, ácido úrico, xantina e hipoxantina e purinas totais e da relação alantoína e ácido úrico:purinas totais; os compostos nitrogenados microbianos ( $\mathrm{N}$ mic) no intestino delgado, estimados pelo método de excreção de derivados de purinas, usando duas relações de $\mathrm{N}$ purina: $\mathrm{N}$ total, sendo usados os valores obtidos para cada experimento; e 0,116, conforme recomendado por CHEN e GOMES (1992); compostos nitrogenados microbianos no abomaso, estimados pelas bases purinas; e os valores médios de MODR e CHODR.

As excreções de derivados de purinas urinários, representados por alantoína, purinas totais e relação alantoína e ácido úrico:purinas totais, apresentaram comportamento quadrático $(\mathrm{P}<0,05)$, com valores máximos de 97,96 e 111,63 mmol/dia e 98,10\%, para níveis de concentrado na ração de 63,76 ; 66,33; e
$50,00 \%$, respectivamente. Esta resposta foi similar à obtida para o fluxo de compostos nitrogenados microbianos, estimado pelos derivados de purinas urinários, usando a relação de $\mathrm{N}$ purina: $\mathrm{N}$ total de 0,116 .

Conforme FUJIHARA et al. (1987) e BRODERICK e MERCHEN (1992), a excreção urinária de derivados de purinas constitui boa alternativa para a estimativa do fluxo de compostos nitrogenados microbianos. No entanto, PUCHALA e KULASEK (1992) sugeriram não realizar todas as análises dos derivados de purinas, mas apenas as de alantoína, já que este derivado de purina reflete a excreção dos mesmos na urina.

A relação alantoína e ácido úrico:purinas totais de, aproximadamente, $98 \%$, indica que a concentração de xantina e hipoxantina dentro dos derivados de purinas seria em torno de $2 \%$ para todos os cinco experimentos estudados, o que está de acordo com LIANG et al. (1994), que encontraram, para zebuínos e búfalos, excreção menor que $3 \%$ do total da excreção de purinas.

As excreções de ácido úrico e xantina e hipoxantina não foram influenciadas pelos níveis de concentrado da dieta e apresentaram valores médios de 9,10 e 1,93 mmol/dia, respectivamente.

O fluxo de compostos nitrogenados microbianos, determinado pela excreção urinária de derivados de purinas, usando a relação $\mathrm{N}$ purina: $\mathrm{N}$ total de cada experimento, apresentou comportamento linear $(\mathrm{P}<0,01)$. Vale ressaltar que a relação média, para os cinco experimentos em conjunto, foi de 0,117 . O fluxo de compostos nitrogenados microbianos, determinado por intermédio da relação $\mathrm{N}$ purina: $\mathrm{N}$ total, sugerido por CHEN e GOMES (1992) de 0,116, apresentou comportamento quadrático $(\mathrm{P}<0,05)$, com valor máximo de 72,07 g N mic/dia, para 62,91\% de concentrado na ração. Quando o fluxo de compostos nitrogenados microbianos foi determinado pelas bases purinas (USHIDA et al., 1985), o comportamento também foi quadrático, utilizando resultados de todos os experimentos, com valor máximo de $86,08 \mathrm{~g} \mathrm{~N} \mathrm{mic/dia,}$ para $63,60 \%$ de concentrado da dieta. Portanto, independente do método de cálculo da produção microbiana, o valor máximo foi obtido entre 62 e $64 \%$ de concentrado. Rode et al. (1985), citados por CLARK et al. (1992), relataram que máxima produção foi encontrada com $62 \%$ de concentrado.

Pode ocorrer diminuição na passagem de proteína microbiana para o intestino delgado, quando se utilizam dietas com mais de $70 \%$ de concentrado, em virtude da alta taxa de degradação de carboidratos 
RENNÓ et al.

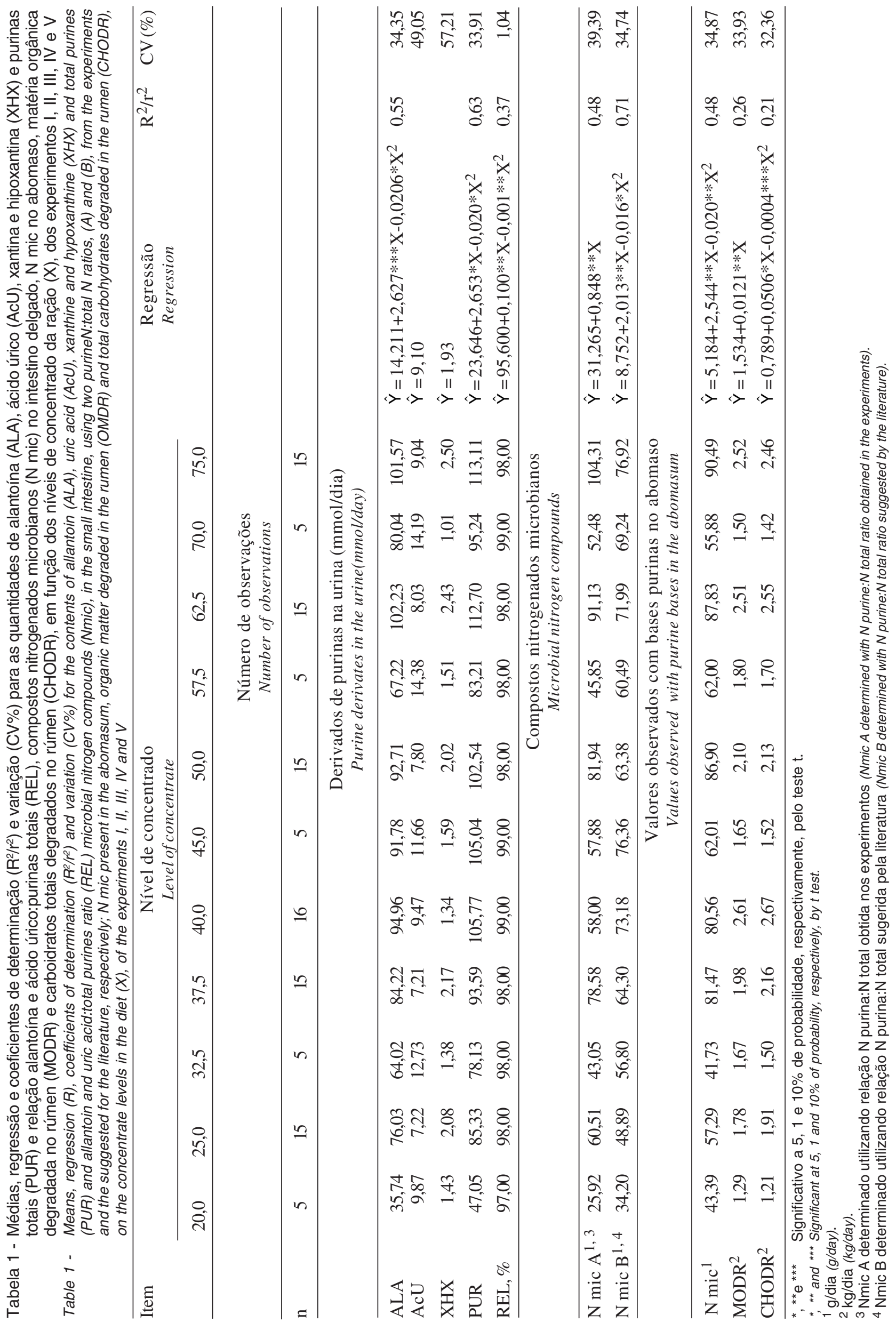


Rev. bras. zootec.

não-estruturais (CNE), resultando em fermentação não-acoplada. O mesmo pode ocorrer quando as dietas contiverem elevados teores de volumosos, o que pode ser atribuído à deficiência de energia disponível e ao aumento da reciclagem de compostos nitrogenados pelos microrganismos do rúmen (CLARK et al., 1992).

Constatou-se comportamento linear crescente $(\mathrm{P}<0,01)$ para o teor de MODR e comportamento quadrático para o teor de CHODR $(\mathrm{P}<0,10)$, em função dos níveis de concentrado na ração, com valor máximo de $2,33 \mathrm{~kg} / \mathrm{dia}$, para $60,71 \%$ de concentrado na ração.
Na Tabela 2, foram agrupados somente os dados dos experimentos I, II e III, por se tratarem de experimentos com animais mestiços e com as mesmas proporções de volumoso e concentrado nas rações, resultando em 75 observações.

As excreções de alantoína e purinas totais também seguiram o comportamento da produção microbiana, demonstrando comportamento linear crescente $(\mathrm{P}<0,01)$, o que está de acordo com FUJIHARA et al. (1987), PUCHALA e KULASEK (1992) e VAGNONI e BRODERICK (1997), que indicaram alta correlação entre excreção de derivados de purinas

Tabela 2 - Médias, regressão e coeficientes de determinação $\left(R^{2} / r^{2}\right)$ e variação $(C V \%)$ para as quantidades de alantoína (ALA), ácido úrico (AcU), xantina e hipoxantina (XHX) e purinas totais (PUR) e relação alantoína e ácido úrico:purinas totais (REL), compostos nitrogenados microbianos ( $\mathrm{N}$ mic) no intestino delgado, $\mathrm{N}$ mic no abomaso, matéria orgânica degradada no rúmen (MODR) e carboidratos totais degradados no rúmen (CHODR), em função dos níveis de concentrado da ração $(X)$, dos experimentos I, II e III

Table 2 - Means, regression and coefficients of determination $\left(R^{2} / r^{2}\right)$ and variation (\%CV) for the contents of allantoin (ALA), uric acid $(A c U)$, xanthine and hypoxanthine $(X H X)$ and total purines (PUR) and allantoin and uric acid:total purines ratio (REL), microbial nitrogen compounds (Nmic), in the small intestine, $N$ mic present in the abomasum, organic matter degraded in the rumen (OMDR) and total carbohydrates degraded in the rumen (CHODR), on the concentrate levels in the diet $(X)$, of the experiments I, II, and III

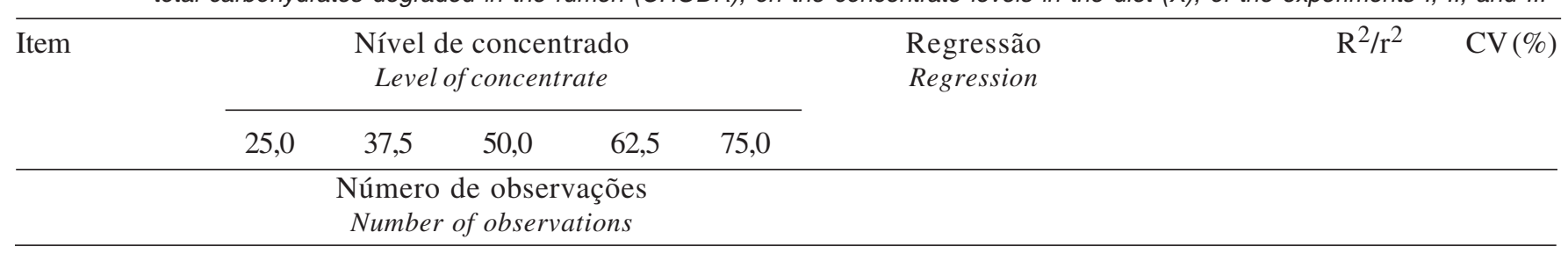

\begin{tabular}{llllll}
\hline $\mathrm{n}$ & 15 & 15 & 15 & 15 & 15
\end{tabular}

Derivados de purinas na urina ( $\mathrm{mmol} / \mathrm{dia})$

Purine derivates in the urine(mmol/day)

\begin{tabular}{lrrrrrlr}
\hline ALA & 76,03 & 84,22 & 92,71 & 102,23 & 101,57 & $\hat{Y}=63,716+0,553 * * X$ & 30,73 \\
AcU & 7,22 & 7,21 & 7,80 & 8,03 & 9,04 & $\hat{Y}=7,86$ & 0,94 \\
XHX & 2,08 & 2,17 & 2,02 & 2,43 & 2,50 & $\hat{Y}=2,24$ & 53,36 \\
PUR & 85,33 & 93,59 & 102,54 & 112,70 & 113,11 & $\hat{Y}=71,595+0,597 * * X$ & 49,50 \\
REL, \% & 98,00 & 98,00 & 98,00 & 98,00 & 98,00 & $\hat{Y}=98,00$ & 30,30 \\
& & & & & & 1,12 \\
\hline
\end{tabular}

Compostos nitrogenados microbianos

Microbial nitrogen compounds

\begin{tabular}{|c|c|c|c|c|c|c|c|c|}
\hline $\mathrm{N} \operatorname{mic} \mathrm{A}^{1,3}$ & 60,51 & 78,58 & 81,94 & 91,13 & 104,37 & $\hat{Y}=43,198+0,802 * * X$ & 0,96 & 38,39 \\
\hline $\mathrm{N} \operatorname{mic} \mathrm{B}^{1,4}$ & 48,89 & 64,30 & 63,38 & 71,99 & 76,92 & $\hat{Y}=39,592+0,511 * * X$ & 0,90 & 33,46 \\
\hline
\end{tabular}

Valores observados com bases purinas no abomaso

Values observed with purine bases in the abomasum

\begin{tabular}{lrrrrrlr}
\hline N mic $^{1}$ & 57,29 & 81,47 & 86,90 & 87,83 & 90,49 & $\hat{Y}=4,159+2,755^{* * X}-0,0217 * * * X^{2}$ & 0,94 \\
MODR $^{2}$ & 1,78 & 1,98 & 2,10 & 2,51 & 2,52 & $\hat{Y}=1,372+0,016 * * X$ & 35,00 \\
CHODR $^{2}$ & 1,91 & 2,16 & 2,13 & 2,55 & 2,46 & $\hat{Y}=1,648+0,012 * X$ & 32,39 \\
\hline
\end{tabular}

${ }^{*},{ }^{* *} \mathrm{e}^{* * *}$ Significativo a 5,1 e $10 \%$ dle probabilidade, respectivamente, pelo teste t.

${ }^{*},{ }^{* *}$ and ${ }^{* * *}$ Significant at 5,1 and $10 \%$ of probability, respectively, by $t$ test.

$1 \mathrm{~g} / \mathrm{dia}(\mathrm{g} / \mathrm{day})$.

$2 \mathrm{~kg} / \mathrm{dia}$ (kg/day).

${ }^{3} \mathrm{Nmic} A$ determinado utilizando relação $\mathrm{N}$ purina: $\mathrm{N}$ total obtida nos experimentos I, II e III (Nmic A determined with N purine:N total ratio obtained in the experiments I, II and III).

${ }^{4} \mathrm{Nmic} B$ determinado utilizando relação $\mathrm{N}$ purina: $\mathrm{N}$ total sugerida pela literatura ( $N$ mic B determined with $\mathrm{N}$ purine: $\mathrm{N}$ total ratio suggested by the literature). 
na urina e fluxo de compostos nitrogenados microbianos no duodeno e, ainda, a excreção de alantoína reflete a excreção total de derivados de purinas, já que é encontrada em maior proporção, em torno de $85 \%$ dos derivados de purinas (VERBIC et al., 1990, VAGNONI et al., 1997).

As excreções de ácido úrico, xantina e hipoxantina e a relação alantoína e ácido úrico:purinas totais apresentaram valores médios de 7,86 e 2,24 mmol/dia e $98 \%$. Pode-se observar que os coeficientes de determinação $\left(\mathrm{R}^{2}\right)$ para produção de compostos nitrogenados microbianos $(0,96 ; 0,90$; e 0,94$)$ e a excreção de alantoína $(0,94)$ e purinas totais $(0,95)$ foram muito próximos entre si e maiores que os citados na Tabela 1, com os dados de todos os experimentos.

O fluxo de compostos nitrogenados microbianos determinado pela excreção urinária de derivados de purinas, usando a relação $\mathrm{N}$ purina: $\mathrm{N}$ total de cada experimento e a de 0,116 , apresentou comportamento linear crescente $(\mathrm{P}<0,01)$. Quando a estimativa do fluxo de compostos nitrogenados microbianos foi obtida por intermédio das bases purinas no abomaso, foi observado comportamento quadrático $(\mathrm{P}<0,10)$, cujo valor máximo foi de $91,60 \mathrm{~g} \mathrm{~N}$ mic/dia, com $63,48 \%$ de concentrado na ração. Vale ressaltar que o nível de significância, para este comportamento, foi de $10 \%$.

$\mathrm{O}$ teor de MODR e CHODR cresceu linearmente, $\mathrm{P}<0,01$ e $\mathrm{P}<0,05$, respectivamente, com os níveis de concentrado da dieta.

Constam da Tabela 3 apenas os dados dos experimentos IV e V, por utilizarem animais zebuínos. A excreção dos derivados de purinas urinários referentes à alantoína e purinas totais e a relação alantoína e ácido úrico:purinas totais demonstraram também comportamento quadrático $(\mathrm{P}<0,01)$, observado para o fluxo dos compostos nitrogenados microbianos. Foram encontrados os valores máximos de 93,50 e $106,55 \mathrm{mmol} / \mathrm{dia}$ e $98,72 \%$ para 50,$48 ; 51,42 ;$ e $53,57 \%$ de concentrado na dieta, respectivamente.

As excreções de ácido úrico e xantina e hipoxantina não foram influenciadas pelos níveis de concentrados, apresentando valores médios de 11,36 e $1,37 \mathrm{mmol} / \mathrm{dia}$, respectivamente.

As estimativas dos compostos nitrogenados microbianos, determinadas pela excreção de derivados de purinas na urina, usando a relação de $\mathrm{N}$ purina: $N$ total de cada experimento e o valor de 0,116 (CHEN e GOMES, 1992), apresentaram comportamento quadrático $(\mathrm{P}<0,01)$, com valores máximos de 57,50 e 75,63 g N mic/dia para 50,84 e 52,36\% de concentrado na ração, respectivamente. Quando este fluxo de compostos nitrogenados microbianos foi determinado pelas bases purinas no abomaso, foi observado também comportamento quadrático ( $\mathrm{P}<0,01)$, cujo valor máximo foi de 73,46 g N mic/dia para $48,38 \%$ de concentrado na dieta. Segundo o ARC (1984), dietas ricas em concentrado, em torno de $70 \%$ ou mais, podem resultar em menor síntese microbiana, decorrente de inadequado suprimento de proteína degradada no rúmen e alta produção de ácido lático, resultando em reduzido suprimento de ATP e menor salivação e ruminação, ocasionando menor taxa de passagem de líquidos e, conseqüentemente, menor fluxo de compostos nitrogenados bacterianos. RUSSELL et al. (1992) citaram que, se a quantidade de fibra dietética for restrita e a taxa de fermentação de carboidratos, rápida, o $\mathrm{pH}$ pode diminuir, visto que estudos in vitro indicaram que a eficiência de síntese protéica microbiana pode diminuir significativamente.

O teor de MODR e CHODR apresentou comportamento quadrático $(\mathrm{P}<0,01)$, em função dos níveis de concentrado da ração; os valores máximos diários foram de 2,35 $\mathrm{kg}$ MODR e 2, $17 \mathrm{~kg}$ CHODR, para 46,00 e $43,83 \%$ de concentrado na dieta, respectivamente.

Observam-se, na Tabela 4 , as equações de regressão entre a quantidade de proteína microbiana sintetizada diariamente, utilizando-se o método das bases purinas no abomaso (USHIDA et al. 1985), correspondente a $\mathrm{Y}$, e a quantidade de derivados de purinas na urina (CHEN e GOMES, 1992), correspondente a X. Os coeficientes de determinação $\left(\mathrm{r}^{2}\right)$ para as regressões entre os métodos de determinação da produção dos compostos nitrogenados microbianos comparados entre os agrupamentos de experimentos foram bem próximos e todos menores que 0,42 .

A Tabela 5 apresenta as médias de compostos nitrogenados microbianos, obtidas a partir da excreção urinária de derivados de purinas, utilizando-se as relações $\mathrm{N}$ purina: $\mathrm{N}$ total de cada experimento e a proposta por CHEN e GOMES, (1992), 0,116, comparadas às médias obtidas a partir das bases purinas, conforme USHIDA et al. (1985).

Para os compostos nitrogenados microbianos, não houve diferença $(\mathrm{P}>0,05)$ em todos os agrupamentos de experimentos e para os animais mestiços, quando se compararam as médias obtidas pelos derivados de purinas na urina, por intermédio da relação $\mathrm{N}$ purina: $\mathrm{N}$ total de cada experimento, com as observadas pelas bases purinas no abomaso. Para os animais zebuínos, não houve diferença $(\mathrm{P}>0,05)$ entre 
Rev. bras. zootec.

Tabela 3 - Médias, regressão e coeficientes de determinação $\left(R^{2} / r^{2}\right)$ e variação $(C V \%)$ para as quantidades de alantoína $(\mathrm{ALA})$, ácido úrico $(\mathrm{AcU})$, xantina e hipoxantina $(\mathrm{XHX})$ e purinas totais (PUR) e relação alantoína e ácido úrico:purinas totais (REL), compostos nitrogenados microbianos ( $\mathrm{N}$ mic) no intestino delgado, $\mathrm{N}$ mic no abomaso determinados pelas bases purinas, matéria orgânica degradada no rúmen (MODR) e carboidratos totais degradados no rúmen (CHODR), em função dos níveis de concentrado da ração (X), dos experimentos IV e $\mathrm{V}$

Table3 - Means, regression and coefficients of determination $\left(R^{2} / r^{2}\right)$ and variation $(C V \%)$ for the contents of allantoin $(A L A)$, uric acid $(A c U)$, xanthine and hypoxanthine (XHX) and total purines (PUR), and allantoin and uric acid:total purines ratio (REL), microbial nitrogen compounds (Nmic), in the small intestine, $N$ mic present in the abomasum, organic matter degraded in the rumen (OMDR) and total carbohydrates degraded in the rumen (CHODR), on the concentrate levels in the diet $(X)$, of the experiments IV and $V$

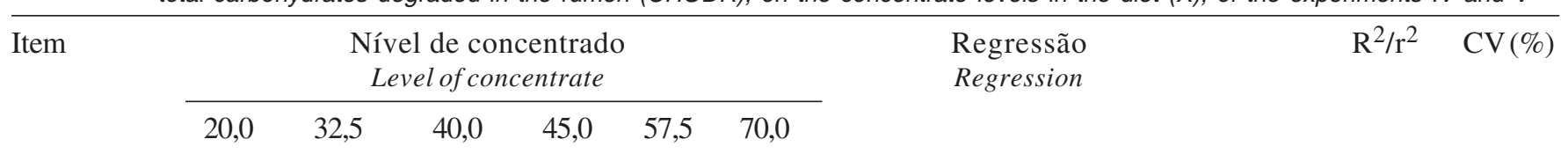

Número de observações

Number of observations

\begin{tabular}{|c|c|c|c|c|c|c|c|c|c|}
\hline $\mathrm{n}$ & 5 & 5 & 16 & 5 & 5 & 5 & & & \\
\hline \multicolumn{10}{|c|}{$\begin{array}{l}\text { Derivados de purinas na urina }(\mathrm{mmol} / \mathrm{dia}) \\
\text { Purine derivates in the urine (mmol/day) }\end{array}$} \\
\hline ALA & 35,74 & 64,02 & 94,96 & 91,78 & 67,32 & 80,04 & $\hat{Y}=-58,865+6,037 * * X-0,0598 * * X^{2}$ & 0,71 & 42,12 \\
\hline $\mathrm{AcU}$ & 9,87 & 12,73 & 9,47 & 11,66 & 14,38 & 14,19 & $\hat{Y}=11,36$ & & 47,78 \\
\hline XHX & 1,43 & 1,38 & 1,34 & 1,59 & 1,51 & 1,01 & $\hat{Y}=1,37$ & & 65,68 \\
\hline PUR & 47,05 & 78,13 & 105,77 & 105,04 & 83,21 & 95,24 & $\hat{Y}=-46,513+5,954 * * X-0,0579 * * X^{2}$ & 0,76 & 41,21 \\
\hline REL, \% & 97,00 & 98,00 & 99,00 & 99,00 & 98,00 & 99,00 & $\hat{Y}=94,700+0,150 * * X-0,0014 * * X^{2}$ & 0,69 & 0,88 \\
\hline
\end{tabular}

Compostos nitrogenados microbianos

Microbial nitrogen compounds

\begin{tabular}{llllllllll}
\hline $\mathrm{N} \mathrm{mic} \mathrm{A}^{1,3}$ & 25,92 & 43,05 & 58,00 & 57,88 & 45,85 & 52,48 & $\hat{\mathrm{Y}}=-25,225+3,254 * * X-0,032 * * \mathrm{X}^{2}$ & 0,76 & 36,74 \\
$\mathrm{~N} \mathrm{mic} \mathrm{B}^{1,4}$ & 34,20 & 56,80 & 73,18 & 76,36 & 60,49 & 69,24 & $\hat{\mathrm{Y}}=-28,531+3,979 * * X-0,038 * * \mathrm{X}^{2}$ & 0,79 & 37,19
\end{tabular}

Valores observados com bases purinas no abomaso

Values observed with purine bases in the abomasum

\begin{tabular}{lrrrrrrrrr}
\hline N mic $^{1}$ & 43,39 & 41,74 & 80,56 & 62,01 & 62,00 & 55,88 & $\hat{\mathrm{Y}}=-22,500+3,967 * * \mathrm{X}-0,041 * * \mathrm{X}^{2}$ & 0,48 & 34,87 \\
MODR $^{2}$ & 1,29 & 1,67 & 2,61 & 1,65 & 1,80 & 1,50 & $\hat{\mathrm{Y}}=-0,825+0,138 * \mathrm{X}-0,0015 * * \mathrm{X}^{2}$ & 0,52 & 37,07 \\
$\mathrm{CHODR}^{2}$ & 1,21 & 1,50 & 2,67 & 1,52 & 1,70 & 1,42 & $\hat{\mathrm{Y}}=-1,092+0,149 * * \mathrm{X}-0,0017 * * \mathrm{X}^{2}$ & 0,46 & 34,89 \\
\hline
\end{tabular}

${ }^{*} e^{* *}$ Significativo a 5 e $1 \%$ de probabilidade, respectivamente pelo teste $t$.

${ }^{*}$ and ${ }^{* *}$ Significant at 5 and $1 \%$ of probability, respectively, by $t$ test.

${ }^{1} \mathrm{~g} /$ dia (g/day).

$2 \mathrm{~kg} / \mathrm{dia}(\mathrm{kg} / \mathrm{day})$

$3 \mathrm{Nmic}$ A determinado utilizando relação N purina: N total obtida nos experimentos IV e V (Nmic A determined with N purine: N total ratio obtained in the experiments IV and $V$ ).

${ }^{4} \mathrm{Nmic} B$ determinado utilizando relação N purina: $\mathrm{N}$ total sugerida pela literatura (Nmic B determined with N purine: $\mathrm{N}$ total ratio suggested by the literature).

as médias de $\mathrm{N}$ microbiano obtidas pelos derivados de purinas na urina, por meio da relação de $\mathrm{N}$ purina: $\mathrm{N}$ total, de 0,116 , com as verificadas pelas bases purinas. Vale ressaltar que o uso de uma relação fixa pode não ser adequada.

Segundo FIRKINS et al. (1998), as variações e os erros permanecem na predição do fluxo de proteína microbiana para o duodeno, quando são usados procedimentos in vivo. Entretanto, quando resultados de experimentos in vivo são agrupados, para se estimar o fluxo de compostos nitrogenados microbianos, em extensa variedade de condições, este poderia ser acuradamente predito por intermédio do consumo de matéria seca (CMS) e da porcentagem de fibra em detergente neutro (FDN) da dieta.

$\mathrm{Na}$ Tabela 6, são apresentadas as equações de regressão para o $\mathrm{N}$ microbiano obtido por dois métodos: derivados de purinas na urina e nas bases purinas, em relação à ingestão de matéria seca (MS) e à porcentagem de FDN da dieta, agrupados em experimentos. Para o método das bases purinas, os coeficientes de determinação são mais altos e os 
Tabela 4 - Regressão e coeficientes de determinação $\left(r^{2}\right)$ e variação (CV\%) para compostos nitrogenados microbianos ( $\mathrm{N}$ mic, g/dia)

Table 4 - Regression and coefficients of determination $\left(r^{2}\right)$ and variation (CV\%) for microbial nitrogen compounds (Nmic, g/day)

\begin{tabular}{|c|c|c|c|c|}
\hline $\begin{array}{l}\text { Animal } \\
\text { Animal }\end{array}$ & $\mathrm{n}$ & $\begin{array}{l}\text { Regressão } \\
\text { Regression }\end{array}$ & $\mathrm{r}^{2}$ & $\mathrm{CV}(\%)$ \\
\hline $\begin{array}{l}\text { Todos } \\
\text { All }\end{array}$ & 116 & $\hat{Y}=35,102+0,554 * * X$ & 0,41 & 30,31 \\
\hline $\begin{array}{l}\text { Mestiços } \\
\text { Crossbred }\end{array}$ & 75 & $\hat{Y}=37,065+0,525 * * X$ & $0,36^{1}$ & 29,33 \\
\hline $\begin{array}{l}\text { Zebuínos } \\
\text { Zebu }\end{array}$ & 41 & $\hat{Y}=24,499+0,784 * * X$ & $0,38^{1}$ & 32,32 \\
\hline
\end{tabular}

** significativo a $1 \%$ de probabilidade pelo teste $\mathrm{t}$ (significant at $1 \%$ by $t$ test).

$\mathrm{n}$ = número de observações (number of observations).

$1 r^{2}$ ajustado (fitted $r^{2}$ ).

Tabela 5 - Médias para nitrogênio microbiano (Nmic, g/dia), determinados pelo método dos derivados de purinas na urina $(A)$ usando relações de $N$ purina: $\mathrm{N}$ total de cada experimento $\left(A_{1}\right)$ e o valor de $0,116\left(A_{2}\right)$ em comparação com a das bases purinas obtidas com coletas de abomaso (B)

Table 5 - Means for microbial nitrogen compounds (Nmic, g/day), determined by the purine bases in the urine method $(A)$ using $N$ purine:total $N$ ratios $\left(A_{1}\right)$, and the value of $116\left(A_{2}\right)$

\begin{tabular}{|c|c|c|c|c|c|c|}
\hline \multirow{3}{*}{$\begin{array}{l}\text { Experimento } \\
\text { Experiment }\end{array}$} & \multirow{3}{*}{$\mathrm{n}$} & \multicolumn{3}{|c|}{$\begin{array}{c}\text { Método } \\
\text { Method }\end{array}$} & \multirow{3}{*}{$\mathrm{A}_{1} \times \mathrm{B}$} & \multirow{3}{*}{$\mathrm{A}_{2} \times \mathrm{B}$} \\
\hline & & \multicolumn{2}{|c|}{ A } & \multirow[t]{2}{*}{ B } & & \\
\hline & & $\mathrm{A}_{1}$ & $\mathrm{~A}_{2}$ & & & \\
\hline $\begin{array}{l}\text { Todos } \\
\text { All }\end{array}$ & 116 & 71,57 & 64,99 & 74,77 & $\mathrm{~ns}$ & $* *$ \\
\hline $\begin{array}{l}\text { Animais mestiços } \\
\text { Crossbred animals }\end{array}$ & 75 & 83,31 & 65,10 & 80,80 & $\mathrm{~ns}$ & $* *$ \\
\hline $\begin{array}{l}\text { Animais zebuínos } \\
\text { Zebu animals }\end{array}$ & 41 & 50,09 & 64,79 & 63,76 & $* *$ & $\mathrm{~ns}$ \\
\hline
\end{tabular}

** significativo a $1 \%$ de probabilidade pelo teste $\mathrm{t}$ (significant at $1 \%$ by $t$ test).

$\mathrm{n}=$ número de observações (number of observations).

coeficientes de variação, mais baixos, em relação ao método dos derivados de purinas na urina.

Aumentos no consumo proporcionam maior escape de compostos nitrogenados microbianos e de $\mathrm{N}$ dietético para o duodeno (CLARK et al. 1992), possivelmente, em virtude do aumento nas taxas de passagem (VAN SOEST, 1994). Em todos os agrupamentos e ambos os métodos de determinação da produção microbiana, houve correlação positiva para produção de $\mathrm{N}$ microbiano e CMS, e negativa para a porcentagem de FDN na dieta.
De acordo com FIRKINS et al. (1998), o fluxo de N microbiano pode ser influenciado pela proporção de forragem e concentrado da dieta, pela porcentagem de FDN, que influencia o $\mathrm{pH}$ ruminal, ou pelo suprimento de proteína degradável no rúmen. A equação de N microbiano (Nmic, g N/dia) foi calculada em função do consumo de PB (CPB, kg/dia) e de FDN (CFDN, kg/dia) da dieta: Nmic $=13,093+108,991^{* *} \mathrm{CPB}-3,816^{* * *} \mathrm{CFDN}$, que apresentou coeficiente de determinação e variação de 0,49 e $34,21 \%$, respectivamente $(* *, * * *$ significativo a 1 e $10 \%$, pelo teste $\mathrm{t}$ ). 
Rev. bras. zootec.

Tabela 6 - Regressão e coeficientes de determinação $\left(R^{2}\right)$ e variação $(C V \%)$ para nitrogênio microbiano $(Y)$ em g/dia obtido por dois métodos:derivados de purinas na urina $(A)$ e bases purinas no abomaso (B) em relação ao consumo de matéria seca (CMS) em $\mathrm{kg} /$ dia e fibra em detergente neutro (FDN) em\% da ração, agrupados para todos os animais, animais mestiços e animais zebuínos

Table 6 - Regression and coefficients of determination $\left(R^{2}\right)$ and variation $(C V \%)$ for microbial nitrogen $(Y)$, in $g /$ day obtained by two methods: purine bases in the urine $(A)$ and purine bases in the abomasum (B) methods on the dry matter intake (DMI), grouped for all animals, crossbred and Zebu animals

\begin{tabular}{lccccc}
\hline $\begin{array}{l}\text { Método } \\
\text { Method }\end{array}$ & $\begin{array}{c}\text { Experimento } \\
\text { Experiment }\end{array}$ & $\mathrm{n}$ & $\begin{array}{c}\text { Regressão } \\
\text { Regression }\end{array}$ & $\mathrm{R}^{2}$ & $\mathrm{CV}(\%)$ \\
\hline $\mathrm{A}$ & Todos & 116 & $\hat{\mathrm{Y}}=57,043+12,610 * *$ CMS-0,968**FDN & 0,52 & 33,32 \\
$\mathrm{~B}$ & All & & $\hat{\mathrm{Y}}=17,993+15,234 *$ CMS-0,357**FDN & 0,72 & 20,96 \\
& & & $\hat{\mathrm{Y}}=50,106+13,574 *$ CMS-0,794**FDN & 0,49 & 29,77 \\
$\mathrm{~A}$ & Animais mestiços & 75 & $\hat{\mathrm{Y}}=14,349+15,677 * *$ CMS-0,306*FDN & 0,69 & 20,83 \\
$\mathrm{~B}$ & Crossbred animals & &
\end{tabular}

\begin{tabular}{lcccrr} 
A & Animais zebuínos & 41 & $\hat{\mathrm{Y}}=7,837+28,809 * *$ CMS-2,294**CMS2-0,650**FDN & 0,53 & 28,80 \\
$\mathrm{~B}$ & Zebu animals & $\hat{\mathrm{Y}}=21,061+14,012 * *$ CMS-0,348**FDN & 0,74 & 21,21 \\
\hline
\end{tabular}

${ }^{*},{ }^{* *} \mathrm{e}^{* * *}$ significantes a 5,1 e $10 \%$ de probabilidade, respectivamente, pelo teste $\mathrm{t}$.

${ }^{*}$ ** and ${ }^{* * *}$ Significant at 5,1 and $10 \%$ of probability, respectively, by $t$ test.

$\mathrm{n}=$ número de observações (number of observations).

\section{Conclusões}

O método da excreção urinária de derivados de purinas pode ser utilizado para estimar a produção de proteína microbiana.

A produção de proteína microbiana pode ser estimada em função do consumo de matéria seca e da porcentagem de fibra em detergente neutro da ração.

A excreção de xantina e hipoxantina, por ser irrisória em bovinos, não necessita ser determinada para a estimativa da excreção urinária de derivados de purinas, podendo-se basear em alantoína e ácido úrico.

\section{Referências Bibliográficas}

AGRICULTURAL AND FOOD RESEARCH COUNCIL AFRC. 1993. Energy and protein requirements of ruminants. Wallingford, UK: CAB International. 159p.

AGRICULTURAL RESEARCH COUNCIL - ARC. 1984. The nutrient requirements of ruminant livestock. $\mathrm{n}^{\circ} 1$. Published by the Agricultural Research Council. England. 45p.

BRODERICK, G.A, MERCHEN, N.R. 1992. Markers for quantifying microbial protein synthesis in the rumen. J. Dairy Sci., 75:2618.

CARDOSO, R.C. Níveis de concentrado em dietas de bovinos $F_{t}$ Limousin x Nelore: consumo, digestibilidade e crescimento microbiano. Viçosa, MG:UFV, 1999. 80p. Tese (Mestrado em Zootecnia) - Universidade Federal de Viçosa, 1999.

CARVALHO, A.U. Níveis de concentrado na dieta de zebuínos:consumo, digestibilidade e eficiência microbiana. Viçosa, MG:UFV, 1996, 112p. Tese (Doutorado em Zootecnia) - Universidade Federal de Viçosa, 1996.

CARVALHO, A.U., VALADARES FILHO, S.C., COELHO DA SILVA, J.F. et al. 1997a. Níveis de concentrado em dietas de zebuínos. 1. Consumo e digestibilidade aparente. R. Bras. Zootec., 26(5):986-995.
CARVALHO, A.U., VALADARES FILHO, S.C., COELHO DA SILVA, J.F. et al. 1997b. Níveis de concentrado em dietas de zebuínos. 3. Eficiência microbiana e população de protozoários ruminais. R. Bras. Zootec., 26(5):1006-1016.

CECAVA, M.J., MERCHEN, N.R., GAY, L.C. et al. 1990. Composition of ruminal bacteria harvested from steers as influenced by dietary energy level, feeding frequency, and isolation techniques. J. Dairy Sci., 73(9):2480-2488.

CHEN, X.B., ØRSKOV, E.R., HOVELL, F.D.D. 1990a. Excretion of purine derivatives by ruminants:endogenous excretion, differences between cattle and sheep. Br. J. Nutr., 63(1):121-129.

CHEN, X.B., GOMES, M.J. 1992. Estimation of microbial protein supply to sheep and cattle based on urinary excretion of purine derivatives - an overview of technical details. (Occasional publication) INTERNATIONAL FEED RESEARCH UNIT. Bucksburnd, Aberdeen:Rowett Research Institute. 21p.

CHEN, X.B., MATHIESON, F.D.D.H., REEDS, P.J. 1990b. Measurements of purine derivates in urine of ruminants using automated methods. J. Sci. Food Agric., 53(1):23-33.

CHEN, X.B., SAMARAWEERA, L., KYLE, D.L. et al. 1996. Urinary excretion of purine derivatives and tissue xantine oxidase (EC 1,2,3,2) activity in buffaloes (Bubalis bubalis) with special reference to differences between buffaloes and Bos taurus cattle. Br. J. Nut., 75:317-407.

CLARK, J.H., KLUSMEYER, T.H., CAMERON, M.R. 1992 Microbial protein synthesis and flows of nitrogen fractions to the duodenum of dairy cows. J. Dairy Sci., 75(8):2304-2323.

DIAS, H.L.C. Consumo, digestibilidade e eficiência microbiana em novilhos $F_{1}$ Limousin $x$ Nelore alimentados com dietas contendo cinco níveis de concentrado. Viçosa, MG: UFV, 1999. 76p. Dissertação (Mestrado em Zootecnia) Universidade Federal de Viçosa, 1999.

FIRKINS, J.L., ALLEN, M.S., OLDICK, B.S. et al. 1998. Modeling ruminal digestibility of carbohydrates and microbial protein flow to the duodenum. J. Dairy Sci., 81(12):3350-3369.

FUJIHARA, T., ØRSKOV, E.R., REEDS, P.J. et al. 1987. The effect of protein infusion on urinary excretion of purine derivatives in ruminants nourished by intragastric nutrition. J. Agric. Sci., 109:7-12. 
FUNABA, M., KENSUKE, K., TSUNENORI, I. et al. 1997. Duodenal flow of microbial nitrogen estimated from urinary excretion of purine derivatives in calves after early weaning. J. Anim. Sci., 75(7):1965-1973.

GIESECKE, D., EHRENTREICH, L., STANGASSINGER, M. 1994. Mammary and renal excretion of purine metabolites in relation to energy intake and milk yield in dairy cows. J. Dairy Sci., 77(8):2376-2381.

JOHNSON, L.M, HARRISON, J.H., RILEY, R.E. 1998. Estimation of the flow of microbial nitrogen to the duodenum using urinary uric acid or allantoin. J. Dairy Sci., 81(9):2408-2420.

LEÃO, M.I., COELHO DA SILVA, J.F. Técnicas de fistulação de abomaso em bezerros. In: CONGRESSO BRASILEIRO DE ZOOTECNIA, 1. REUNIÃO ANUAL DA SOCIEDADE BRASILEIRA DE ZOOTECNIA, 17, 1980, Fortaleza. Anais... Fortaleza: SBZ, 1980. p.37.

LENINGHER, A.L., NELSON, D.L., COX, M.M. 1995. Princípios de bioquímica. 2.ed., São Paulo: Savier. 839p.

LiAnG, J.B., MATSUMOTO, M., YONG, B.A. 1994. Purine derivative excretion and ruminal microbial yield in Malaysian cattle and swamp buffalo. Anim. Feed Sci. Technol., 47(3/4):189-199.

MOSCARDINI, S., WRIGHT, T.C., LUIMES, P.H. et al. 1998. Effects of rumen-undegradable protein and feed intake on purine derivate and urea nitrogen:comparison with predictions from the Cornell Net Carbohydrate and protein system. J. Dairy Sci., 81(9):2421-2329.

MURA, U., OSMAN, A.M., MOHAMED, A.S. et al. 1986. Studies on purine turnover in the camel (Camelus dromedarius) and zebu (Bos indicus). Comp. Biochem. Physiol., 84B(4):589-593.

NATIONAL RESEARCH COUNCIL - NRC. 1984. Nutrient requirements of beef cattle. 6 ed. Washington: National Academic Press. 90p.

NATIONAL RESEARCH COUNCIL - NRC. 1985. Ruminant nitrogen usage. Washington D.C. 138p.

NATIONAL RESEARCH COUNCIL - NRC. 1996. Nutrient requirements of beef cattle. 7.ed. Washington National Academy. 242p.

NOCEK, J.E., RUSSELL, J.B. 1988. Protein and energy as an integrated system. Relationship of ruminal protein and carbohydrate availability to microbial synthesis and milk production. J. Dairy Sci., 71:2070-2107.

PEREZ, J.F., BALCELLS, J., GUADA, J.A. et al. 1996. Determination of rumen microbial-nitrogen production in sheep:a comparison of urinary purine excretion with methods using ${ }^{15} \mathrm{~N}$ and purine bases as markers of microbial-nitrogen entering the duodenum. Br. J. Nut., 75:699-709.

PUCHALA, R., KULASEK, G.W. 1992. Estimation of microbial protein flow from the rumen of sheep using microbial nucleic acid and excretion of purine derivatives. Can. J. Anim. Sci., 72:821-830.

RIBEIRO, K.G. Rendimento forrageiro e valor nutritivo do capim Tifton-85, sob diferentes doses de nitrogênio e idades de rebrota, e na forma de feno, com bovinos. Viçosa, MG: UFV, 1999. Tese (Doutorado em Zootecnia) - Universidade Federal de Viçosa, 1999.
RUSSELL, J.B., O'CONNOR, J.D., FOX, D.J. et al. 1992. A net carbohydrate and protein system for evaluating cattle diets: I. Ruminal fermentation. J. Anim. Sci., 70(11):3551-3561.

SNIFFEN, C.J., ROBINSON, P.H. 1987 Microbial growth and flow as influenced by dietary manipulations. J. Dairy Sci., 70:425-441,

STANGASSINGER, M., CHEN, X.B., LINDBERG, J.E. et al. 1995. Metabolism of purines in relation to microbial prodution. In: ENGELHARDT, W.V., LEONHARD-MAREK, S., BREVES, G., GIESECKE, D. (Eds.) Ruminant physiology: digestion, metabolism, growth and reprodution. Proceedings of the Eighth International Symposium on Ruminant Physilogy. Stuttgart: Ferdinand Enke Verlag. p.387-406.

TIBO, G.C. Niveis de concentrado na dieta de novilhos mestiços $F_{1}$ SimentalxNelore: consumo, digestões totais e parciais e eficiência microbiana. Viçosa, MG: UFV, 1999. 78p. Dissertação (Mestrado em Zootecnia) - Universidade Federal de Viçosa, 1999.

UNIVERSIDADE FEDERAL DE VIÇOSA - UFV. 1995. Sistema de análises estatísticas e genética - SAEG. Viçosa, MG: UFV. (Apostila).

USHIDA, K., LASSALAS, B., JOUANY, J.P. 1985. Determination of assay parameters for RNA analysis in bacterial and duodenal samples by spectrophotometry. Influence of sample treatment and preservation. Reprod. Nutr. Develop., 25(6):1037-1046.

VAGNONI, D.B., BRODERICK, G.A. 1997. Effects of supplementation of energy or ruminally undegraded protein to lactating cows fed alfafa hay or silage. J. Dairy Sci., 80(8):1703-1712.

VAGNONI, D.B., BRODERICK, G.A., CLAYTON, M.K. et al. 1997. Excretion of purine derivates by Holstein cows abomasally infused with incremental amounts of purines. J. Dairy Sci., 80(8):1695-1702.

VALADARES FILHO, S.C. Eficiência de síntese de proteína microbiana, degradação ruminal e digestibilidade intestinal da proteína bruta, em bovinos. In: SIMPÓSIO INTERNACIONAL SOBREEXIGÊNCIAS NUTRICIONAIS DE RUMINANTES, 1995, Viçosa. Anais... Viçosa: UFV/ DZO, 1995. p.355-388.

VALADARES, R.F.D., GONÇALVES, L.C., SAMPAIO, I.B. et al. 1997. Níveis de proteína em dietas de bovinos. 2. Consumo, digestibilidades e balanços de compostos nitrogenados. R. Bras. Zootec., 26(6):1259-1263.

VAN SOEST, P.J. 1994. Nutritional ecology of the ruminant. 2.ed., Cornell University, Ithaca. 476p.

VERBIC, J., CHEN, X.B., MACLEOD, N.A. et al. 1990. Excretion of purine derivatives by ruminants. Effect of microbial nucleic acid infusion on purine derivative excretion by steers. J. Agric. Sci., 114(3):243-248.
Recebido em: 02/07/1999 Aceito em: 13/10/1999 